\title{
Embedding Socially Responsible Practices within and across the Curriculum: Where We Have Been and What's Next - An ESRAP Panel
}

\author{
Connie Ulasewicz, San Francisco State University
}

Source of Submission: Educators for Socially Responsible Apparel Practices (ESRAP) Steering Committee

Panel Presenters: Marsha Dickson - University of Delaware | Janet Hethorn - Central Michigan University | Young-A Lee - Iowa State University | Sonya Meyer - University of Idaho | Anupama Pasricha - St. Catherine University | Connie Ulasewicz, Moderator - San Francisco State University

Attendees: Over 50 from various programs and schools.

Educators for Socially Responsible Apparel Businesses (ESRAB) was founded in 1999 with the emphasis on increasing awareness and impact of the research and teaching of faculty engaged with social responsibility topics. Our session began with an overview of ESRAB's 15 year history, highlighting how it's members led numerous special sessions that convened faculty and graduate students from over 90 colleges and universities around the globe. Panel members highlighted how their fellow faculty members and graduate students engage with ESRAB's initiatives and share a passion about social responsibility issues in our industry, and a desire to help create solutions. Connections made through ESRAB have led to numerous faculty collaborations. Panel members shared their participation in and with publications, grants, curriculum development, and initiatives engaging industry, that have broadened and deepened their knowledge in particular around corporate social responsibility (CSR) issues and how they can be addressed.

To highlight what's next, members explained the reason for why in 2014 at the ITAA conference committee meeting, ESRAB members voted to update their committee name to Educators for Socially Responsible Apparel Practices (ESRAP). Panel members described how they wanted to deliberately broaden the focus of change to socially responsible practices rather than limiting to the realm of business. The audience was then asked for questions and comments regarding ESRAP and further given information regarding how they too could be a part of this ITAA group.

The interactive session then proceeded forward with an exploration regarding how the integration and development of concepts into practices imbedded across curriculum allows students to highlight work that integrates these practices in their textile, design and 
merchandising projects. Panelists each had the opportunity to share their specific assignments citing examples of how social responsibility and sustainability are taught across the curriculum, rather than as standalone "social responsibility, or sustainable fashion classes" or as simply included within introductory courses. Audience participation further directed the session with questions regarding how to holistically integrate content of social responsibility and sustainability within existing apparel design, product development, consumer behavior, and merchandising curriculumn.

The session ended with a dialogue regarding our students, and how if they are truly going to be prepared to influence and be a part of industry change, we must guide them to model the holistic integration of the values and vision of social responsibility and sustainable fashion throughout our curriculum. Examples of student work were highlighted, envisioning them as change agents as they move forward in their careers in the industry.

This session was beneficial for all attendees, who recognized the existence and accomplishments of ESRAP, and where provided with contacts and tools to be a part of the next adventures of Educators for Socially Responsible Apparel Practices. 